\title{
PEMANFAATAN ABU KULIT KAKAO UNTUK PEMBUATAN BATU BATA
}

\author{
Mulyazmi, Erti Praputri, Zulfiandriana, dan Widya Wahyuni \\ Jurusan Teknik Kimia, Fakultas Teknologi Industri, Universitas Bung Hatta \\ Jl. Gajah Mada No.19, Olo Nanggalo Padang-25143 \\ Email:mulyazmi@yahoo.com
}

\begin{abstract}
Brick is one of building materials derived from clay. The manufacturing process is with or without the use of substances mixing with the process of combustion at high temperatures. One of the mixing substances is derived from the rind cacao ash and its function is as an adhesive on the bricks. The purpose of this research is to understand the characteristics of brick as effect of cocoa rind as the value of compressive strength, porosity, water absorption and weight of a brick. The main materials of brick production are clays and trass ground which are mixed homogeneous with ratio $1: 2$ by varying cocoa rind ash additional by $5 \%, 10 \%$, and $15 \%$. The result is the compressive strength of the bricks using rind cocoa ash is $392.2 \mathrm{~kg} / \mathrm{cm}^{3}$ higher value than traditional brick is $56.1 \mathrm{~kg} / \mathrm{cm}^{3}$.
\end{abstract}

Keywords: Brick, cocoa rind ash, compressive strength

\section{PENDAHULUAN}

Batu bata merupakan salah satu konstruksi bahan bangunan yang banyak digunakan seperti: pembuatan pondasi, dinding pada bangunan, pagar, saluran irigasi dan lainnya. Salah satu fungsi batu bata adalah sebagai penyangga beban yang berada di atasnya.

Bahan batu bata berasal dari tanah liat ditambah air dengan atau tanpa bahan campuran dengan melakukan proses pembakaran pada suhu tinggi ${ }^{[1,2]}$. Salah salah satu bahan pencampuran tersebut adalah abu yang berasal dari kulit buah kakao. Kakao merupakan hasil perkebunan yang banyak tumbuh di Indonesia. Kulit kakao dapat dijadikan sebagai bahan tambahan untuk membuat batu bata.

Kulit buah kakao merupakan produk samping dari pengolahan biji kakao. Sekitar 74\% komposisi kulit kakao dari buah coklat matang belum dimanfaatkan secara optimal, sehingga hanya menjadi limbah produk pertanian ${ }^{[3]}$.
Kandungan abu limbah kulit kakao dapat berfungsi sebagai clay untuk pembuatan batu semen. Dengan demikian abu hasil pembakaran kulit kakao dapat dijadikan batu bata kuat dan tidak mudah pecah karena didalamnya mengandung $71 \% \quad \mathrm{SiO}_{2}$ yang merupakan bahan utama dalam pembuatan semen ${ }^{[4-6]}$.

Kondisi Sumatera Barat khususnya kota Padang yang rawan gempa, membutuhkan batu bata yang ringan dan daya tahan yang kuat. Penelitian ini bertujuan untuk mencari komposisi yang tepat pada batu bata dari abu pembakaran kulit kakao.

\section{METODOLOGI PENELITIAN}

\section{Bahan}

Bahan pembuatan batu bata berupa tanah liat, tanah trass, air, dan campuran abu kulit kakao sebanyak $5 \%, 10 \%$, dan $15 \%$. 


\section{Peralatan}

Alat yang digunakan pada penelitian ini adalah: ayakan, tangki pencampuran, cetakan batu bata dan furnace.

\section{Prosedur Penelitian}

Pembuatan batu bata dari tanah liat dengan cara mencampurkan abu pembakaran kulit kakao dicetak dengan cara pemadatan, pengeringan dan dibakar pada suhu $600{ }^{\circ} \mathrm{C}$ hingga $1000{ }^{\circ} \mathrm{C}$ di dalam Furnace. Pengujian dilakukan terhadap karakteristik sifat-sifat mekanik dan fisis, seperti; kuat tekan, porositas, densitas, dan penyerapan air. Porositas batu bata ditentukan dengan $\operatorname{cara}^{[7,8]}$ :

$$
\operatorname{porositas}(\%)=\frac{m b-m k}{V b} \times \frac{1}{\rho a i r} \times 100 \%
$$

Di mana:

$m b$ : massa basah dari benda uji (gram)

$m k$ : massa kering dari benda uji (gram)

$V b$ : volume benda uji $\left(\mathrm{cm}^{3}\right)$

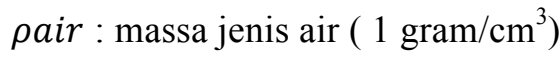

Daya serap air batu bata adalah $[6,7]$ :

$$
P=\frac{W b-W k}{W k} \quad 100 \%
$$

dimana:

$$
\begin{aligned}
P \quad= & \text { persentase air yang terserap bata } \\
W b= & \text { berat bata setelah direndam air } \\
W k= & \text { berat bata kering mutlak sebelum } \\
& \text { direndam air }
\end{aligned}
$$

Batu bata dibuat dengan campuran $0 \%, 5 \%$, $10 \%, 15 \%$ abu pembakaran kulit kakao dan tanah liat terhadap volume massa total dan dibandingkan hasilnya terhadap batu bata yang diproduksi oleh pabrik tradisional.

\section{HASIL DAN DISKUSI}

\section{Penambahan Abu Kulit Kakao terhadap Kuat Tekan Batu Bata pada Berbagai Kondisi Suhu}

Gambar 1 Menunjukkan bahwa kuat tekan pada penambahan abu kulit kakao sebanyak $5 \%$ pada suhu $600{ }^{\circ} \mathrm{C}$ adalah $96,4 \mathrm{~kg} / \mathrm{cm}^{2}$, pada suhu $800{ }^{\circ} \mathrm{C}$ meningkat menjadi 132,6 $\mathrm{kg} / \mathrm{cm}^{2}$, dan peningkatan suhu pembakaran menjadi $1000{ }^{\circ} \mathrm{C}$ adalah $217,5 \mathrm{~kg} / \mathrm{cm}^{2}$. Penambahan abu kulit kakao sebanyak $10 \%$ mempunyai nilai kuat tekan sebesar 133,4 $\mathrm{kg} / \mathrm{cm}^{2}$ pada suhu $600{ }^{\circ} \mathrm{C}, 173,9 \mathrm{~kg} / \mathrm{cm}^{2}$ pada $800{ }^{\circ} \mathrm{C}, 273,4 \mathrm{~kg} / \mathrm{cm}^{2}$ pada $1000{ }^{\circ} \mathrm{C}$. Penambahan abu kulit kakao sebanyak $15 \%$ mempunyai nilai kuat tekan sebesar 170,85 $\mathrm{kg} / \mathrm{cm}^{2}$ pada suhu $600{ }^{\circ} \mathrm{C}, 282,3 \mathrm{~kg} / \mathrm{cm}^{2}$ pada $800{ }^{\circ} \mathrm{C}$, dan meningkat menjadi $392,2 \mathrm{~kg} / \mathrm{cm}^{2}$ pada suhu $1000{ }^{\circ} \mathrm{C}$. Berdasarkan keterangan tersebut menunjukkan bahwa kuat tekan akan meningkat seiring meningkatnya persentase penambahan abu kulit kakao dan suhu pembakaran batu bata.

Kondisi ini sesuai dengan teori, yang menyatakan bahwa kuat tekan akan meningkat seiring dengan penambahan abu kulit kakao ${ }^{[9]}$. Peningkatan kuat tekan ini disebabkan oleh penambahan abu kulit kakao pada batu bata, dimana abu kulit kakao memiliki kandungan senyawa silica $\left(\mathrm{SiO}_{2}\right)$. Abu kulit kakao dapat berperan sebagai pengisi antara pertikel-partikel pembentuk batu bata, sehingga adanya abu kulit kakao maka porositas batu bata akan menjadi lebih kecil sehingga kedapan air batu bata menjadi bertambah sehingga kerapatan batu bata bertambah.

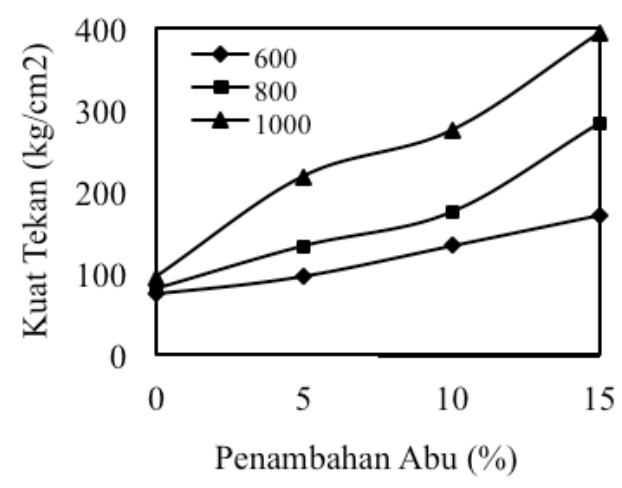

Gambar 1. Pengaruh suhu dan penambahan abu kulit kakao terhadap kuat tekan batu bata. 
Pengaruh Suhu dan Penambahan Abu Kulit Kakao terhadap Porositas Batu Bata

Gambar 2 menunjukkan bahwa porositas pada penambahan abu kulit kakao sebanyak $5 \%$ pada suhu $600{ }^{\circ} \mathrm{C}$ adalah $35,3 \%$, pada suhu $800{ }^{\circ} \mathrm{C}$ menurun menjadi $34,4 \%$, dan peningkatan suhu pembakaran menjadi $1000{ }^{\circ} \mathrm{C}$ adalah $26,4 \%$. Porositas batu bata penambahan abu kulit kakao sebanyak $10 \%$ pada suhu $600{ }^{\circ} \mathrm{C}$ sebesar $35,3 \%$, pada suhu pembakaran $800{ }^{\circ} \mathrm{C}$ sebesar $31,7 \%$, dan pada suhu $1000{ }^{\circ} \mathrm{C}$ menurun menjadi $25,5 \%$. Penambahan abu kulit kakao sebanyak $15 \%$ pada suhu $600{ }^{\circ} \mathrm{C}$ sebesar $32,6 \%$, pada suhu pembakaran $800{ }^{\circ} \mathrm{C}$ sebesar $30,8 \%$, dan pada suhu $1000{ }^{\circ} \mathrm{C}$ menurun menjadi $22,9 \%$.

Kondisi ini menunjukkan bahwa porositas batu bata akan menurun seiring meningkatnya persentase penambahan abu kulit kakao. Di samping itu dapat dilihat bahwa porositas akan menurun seiring meningkatnya suhu pembakaran batu bata. Hal ini berkaitan erat dengan hasil uji kuat tekan. Semikin tinggi kuat tekan maka semakin rendah porositas dan semakin rendah kuat tekan semakin tinggi porositas $^{[9,11]}$.

Pengaruh Suhu dan Penambahan Abu Kulit Kakao terhadap Penyerapan Air Batu Bata

Gambar 3 menunjukkan bahwa penyerapan air pada penambahan abu kulit kakao sebanyak $5 \%$ pada suhu $600{ }^{\circ} \mathrm{C}$ adalah $27 \%$, pada suhu $800{ }^{\circ} \mathrm{C}$ menurun menjadi $26 \%$, dan peningkatan suhu pembakaran menjadi $1000{ }^{\circ} \mathrm{C}$ menurun menjadi $20 \%$. Penambahan abu kulit kakao sebanyak $10 \%$ pada suhu $600{ }^{\circ} \mathrm{C}$ sebesar $26 \%$, pada suhu pembakaran $800{ }^{\circ} \mathrm{C}$ menurun sebesar $24 \%$, dan pada suhu $1000{ }^{\circ} \mathrm{C}$ menurun menjadi $19 \%$. Penambahan abu kulit kakao sebanyak $15 \%$ pada suhu $600{ }^{\circ} \mathrm{C}$ sebesar $24 \%$, pada suhu pembakaran $800{ }^{\circ} \mathrm{C}$ sebesar $23 \%$, dan pada suhu $1000{ }^{\circ} \mathrm{C}$ menurun menjadi $17 \%$.

\section{Pengaruh Suhu dan Penambahan Abu Kulit Kakao terhadap Berat Batu Bata}

Gambar 4 menunjukkan bahwa penurunan berat yang terbesar terdapat pada suhu pembakaran $1000{ }^{\circ} \mathrm{C}$, yaitu sebesar $1460 \mathrm{~g}$. Pada suhu pembakaran $600{ }^{\circ} \mathrm{C}$ dan $800{ }^{\circ} \mathrm{C}$ nilainya sama yaitu sebesar 1500 g. Hal ini disebabkan oleh proses pembakaran. Pada suhu $1000{ }^{\circ} \mathrm{C}$ terjadi proses penguapan yang diikuti dengan proses pemadatan bahan saat suhu pembakaran sangat tinggi maka proses pemadatan akan semakin besar ${ }^{[11]}$.

\section{Perbandingan Batu Bata Penambahan Abu Kulit Kakao dengan Batu Bata Biasa}

Dari hasil penelitian yang telah dilakukan penambahan abu kulit kakao pada pembuatan batu bata akan meningkatkan kualitas batu bata dibandingkan dengan batu bata tanpa penambahan abu kulit kakao. Hal ini terlihat pada Tabel 1.

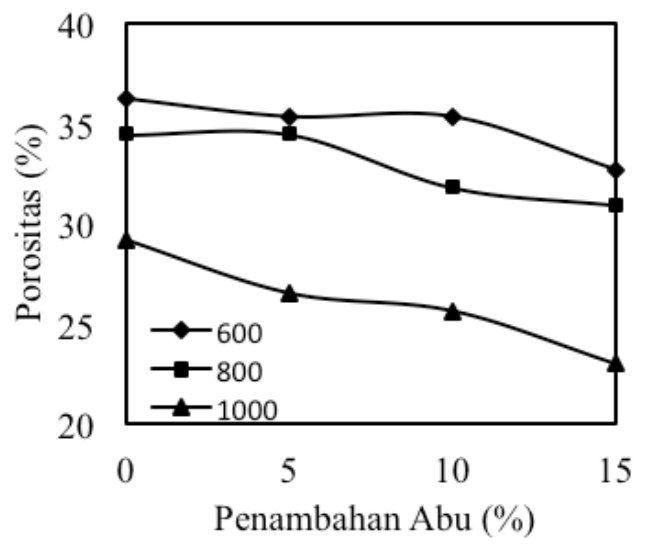

Gambar 2. Pengaruh suhu dan penambahan abu kulit kakao terhadap porositas batu bata.

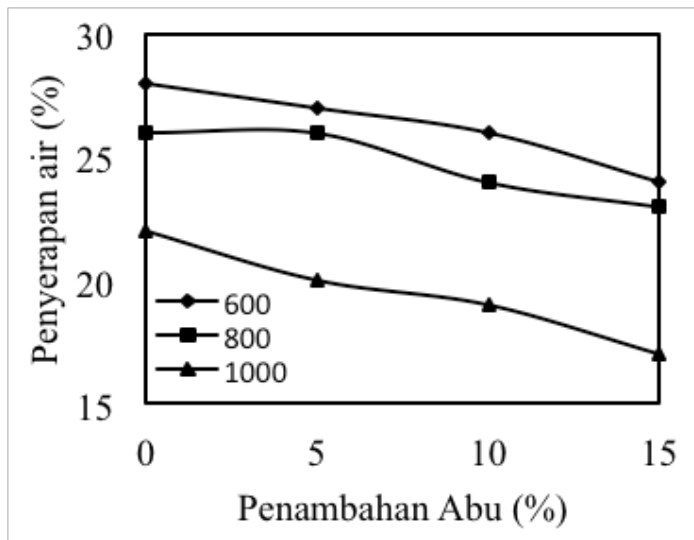

Gambar 3. Pengaruh suhu dan penambahan abukulit kakao terhadap penyerapan air batu bata. 


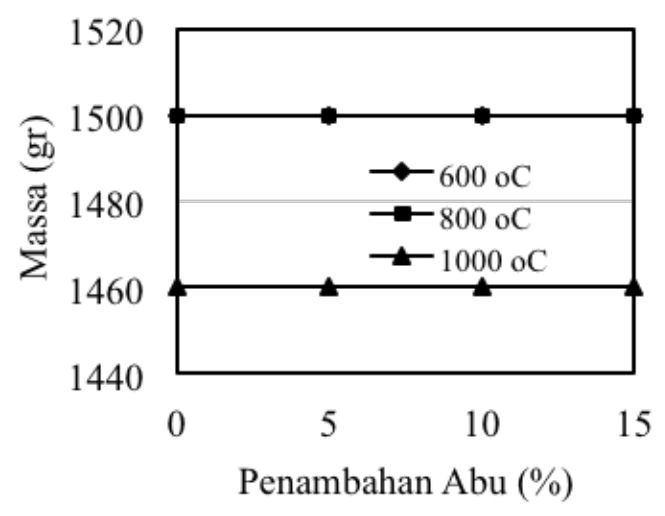

Gambar 4. Pengaruh suhu dan penambahan abu kulit kakao terhadap densitas batu bata.

Tabel 1. Hasil perbandingan batu bata biasa dengan batu bata penambahan abu kulit kakao

\begin{tabular}{ccccc}
\hline \multirow{2}{*}{$\begin{array}{c}\text { Abu } \\
(\%)\end{array}$} & \multicolumn{4}{c}{ Kuat Tekan $\left(\mathrm{kg} / \mathrm{cm}^{2}\right)$} \\
\cline { 2 - 5 } & $600{ }^{\circ} \mathrm{C}$ & $800{ }^{\circ} \mathrm{C}$ & $1000{ }^{\circ} \mathrm{C}$ & Biasa \\
\hline 0 & 73,3 & 80,3 & 94,35 & \\
5 & 96,4 & 132,6 & 217,5 & 56,1 \\
10 & 133,4 & 173,9 & 274,4 & \\
15 & 170,85 & 282,3 & 392,2 & \\
\hline
\end{tabular}

\section{KESIMPULAN}

Kuat tekan batu bata tertinggi diperoleh sebesar $392,2 \mathrm{~kg} / \mathrm{cm}^{3}$ pada suhu pembakaran $1000{ }^{\circ} \mathrm{C}$ dengan penambahan abu kulit kakao $15 \%$. Porositas terbaik diperoleh sebesar $22,9 \%$ pada suhu pembakaran $1000{ }^{\circ} \mathrm{C}$ dengan penambahan abu kulit kakao $15 \%$. Penyerapan air terkecil adalah $17 \%$ pada bata $1000{ }^{\circ} \mathrm{C}$ dengan penambahan abu kulit kakao $15 \%$. Batu bata dengan penambahan abu kulit kakao lebih baik daripada batu bata biasa memiliki kuat tekan di atas $56,1 \mathrm{~kg} / \mathrm{cm}^{2}$.

\section{DAFTAR PUSTAKA}

1. Sudarsana I K. dkk, Karakteristik Batu Bata Tanpa Pembakaran Terbuat Dari Abu Sekam Padi Dan Serbuk Batu
Tabas, Jurnal Ilmiah Teknik Sipil 15(1) (2011).

2. Anonim. Optimasi Pembakaran Batu Bata Merah Dengan Penambahan Limbah Batu Bara Untuk Meningkatkan Kualitas Batu Bata Merah.(http://hfidiyjateng.or.id/sites/d efault/files/18/FULL) (2010).

3. Harsini T. dan Susilowati, Pemanfaatan kulit buah kakao dari limbah perkebunan kakao sebagai bahan baku pulp dengan proses organosol. Jurnal Ilmiah Teknik Lingkungan 2(2) (2010).

4. Handayani, Sri. Kualitas batu bata merah dengan penambahan serbuk gergaji. Jurnal Teknik Sipil dan Perencanaan, 12(1): 41-50 (2010).

5. Ramli, dkk. Pengaruh Pemberian Material limbah Serat Alami Terhadap Sifat Fisik Bata Merah. Penelitian Daerah Dosen Muda Universitas Negeri Padang (2007)

6. Siregar, N. Pemanfaatan Abu pembakaran Ampas Tebu Dan Tanah Liat Pada Pembuatan Batu bata, Skripsi, Medan (2009).

7. Oscar F. N., Analisa sifat fisis dan mekanis batu bata berdasarkan sumber lokasi dan posisi batu bata dalam proses pembakaran, Jurnal Rekayasa Sipil 4(2) (2008).

8. Susatyo Adi Pramono dkk, Sampah Sebagai Bahan Baku Pembuatan Batu Bata, Prosiding Semnas Entrepreneuship, 275-294 (2014).

9. Mulyati, Sri. Pengaruh Persen Massa Hasil Pembakaran Serbuk Kayu dan Ampas TEbu Pada Mortal Terhadap Sifat Mekanik Dan Sifat Fisiknya.. FMIPA UNAND (2014).

10. Alaa A. Shakir dkk, Properties of bricks made using fly ash, quarry dust and billet scale. Jurnal Construction and Building Material. 41: 131-138 (2013).

11. Lianyang Zhang, Production of bricks from waste materials - A review. J. Construction and Building Material. 47: 643-655 (2013). 